\title{
Determinación de daño genético en comerciantes de plaguicidas en el departamento de Matagalpa
}

Inti Luna-Avilés ${ }^{1}$, Richard Gminski ${ }^{2}$, Volker Mersch-Sundermann² y Jorge A. Huete-Pérez ${ }^{1}$ Centro de Biología Molecular (CBM). Facultad de Ciencia, Tecnología y Ambiente. Universidad Centroamericana, Rotonda Rubén Darío, 500mts al oeste, Apto. Postal 69. Managua, Nicaragua. Tel: 278-3923 Ext. 1189. E-mail: intiluna@gmail.com

Instituto de Toxicología Ambiental y de Interiores. Facultad de Medicina. Universidad Justus-Liebig-Giessen, Alemania

Recibido: octubre de 2007 / Aceptado: noviembre de 2007

EL DAÑO CITOGENÉTICO ASOCIADO CON PLAGUiCIDAS POR PARTE de comerciantes de agroquímicos fue evaluado en el departamento de Matagalpa analizando micronúcleos en células bucales (MNBC). Así mismo, fue evaluada la exposición crónica a plaguicidas usando la prueba de acetilcolinesterasa y adicionalmente se identificaron mutaciones de manera exploratoria en el gen CYP2D6, implicado en el metabolismo de plaguicidas. La comparación entre comerciantes de plaguicidas y controles reveló diferencias significativas en las frecuencias de MNBC (6.23 \pm 2.2 vs. $3.63 \pm 1.3 \mathrm{MN} / 2000 \mathrm{MNBC}, \mathrm{P}<0.001$, $\mathrm{t}$ de student). Niveles de colinesterasa indican efecto neurotóxico crónico en los comerciantes de plaguicidas. Estos comerciantes utilizan poco o ningún equipo de protección personal así como medidas de seguridad. Este es el primer estudio a nivel nacional que reporta efecto citogenético de exposición crónica a plaguicidas en comerciantes expuestos.

Palabras clave: genética molecular / comerciantes / plaguicidas / pruebas clínicas / Nicaragua-Matagalpa

\section{Introducción}

En Nicaragua, el manejo inadecuado de plaguicidas cobra cientos de vidas cada año (MINSA, 2006), tanto en condiciones laborales como fuera de éstas. En varias zonas agrícolas del país se presenta un panorama donde existe alto consumo de plaguicidas y poco control sobre el uso e implementación de equipos y medidas de seguridad. A pesar de que en los últimos años este tema ha tenido mayor importancia a nivel mundial, hasta ahora no se han considerado las implicaciones genéticas que este tipo de sustancia puede tener sobre la población que la manipula.

Entre los efectos de los plaguicidas en la salud humana los de mayor relevancia son las intoxicaciones agudas o crónicas, los efectos al sistema inmunológico, el efecto neurotóxico, los efectos endocrinos, la toxicidad reproductiva, los efectos genéticos y la carcinogénesis. El principal mecanismo de intoxicación por plaguicidas es la inhibición de la enzima 
acetilcolinesterasa, que es responsable de controlar el neurotransmisor acetilcolina y por lo tanto, es monitoreada para evaluar la exposición a plaguicidas. Cuando la colinesterasa es inhibida por un plaguicida con estructura similar, se produce un descontrol en la transmisión de impulsos los nerviosos, lo cual puede conllevar parálisis y muerte (INCAP et al., 1999).

Según PLAGSALUD et al. (2003), el Istmo Centroamericano ha sido uno de los mayores consumidores de plaguicidas del mundo, habiendo importado aproximadamente 1.5 kilogramos de plaguicidas per cápita sólo en el año 2000. Muchos de los plaguicidas actualmente utilizados en Centroamérica son extremada o altamente tóxicos, probados carcinógenos, neurotóxicos, toxinas reproductivas o disruptores endocrinos en animales, muchos de ellos prohibidos o estrictamente controlados en países industrializados (Wesseling et al., 2001; Henao \& Arbelaez, 2002).

El daño al ADN es la alteración del material genético y su medida es de gran interés debido a que la mayoría de las sustancias carcinogénicas son genotóxicas. Evaluando el daño genético se tendría un punto de partida a un riesgo mayor como es el cáncer (Albertini $e t$ al., 2000).

Anivel centroamericano existe poca información sobrelos efectos genotóxicos en la población. Sólo tres estudios en esta región se han enfocado en el daño al ADN humano. Todos fueron realizados en Costa Rica y se han limitado, en gran parte, a realizar la investigación con trabajadores de plantaciones bananeras. Por lo tanto, en este estudio se determinó el daño citogenético en comerciantes de plaguicidas y en población no expuesta ocupacionalmente a estas sustancias, en el departamento de Matagalpa. Se seleccionó el departamento de Matagalpa por el gran número de agroservicios existentes en él y por presentar un alto índice de intoxicaciones agudas.

\section{Objetivos}

\section{Objetivo general}

Determinar daño en ADN de comerciantes de plaguicidas inhibidores de colinesterasa en el departamento de Matagalpa, Nicaragua.

\section{Objetivos específicos}

- Determinar el nivel de daño al ADN de comerciantes de plaguicidas inhibidores de colinesterasa, utilizando el ensayo de micronúcleos en células bucales.

- Determinar el nivel de colinesterasa eritrocitaria como parámetro para valorar la exposición crónica a plaguicidas.

- Relacionar algunos factores del ambiente laboral y hábitos personales con el daño genético en los comerciantes.

- Determinar polimorfismo de gen CYP2D6 de susceptibilidad genética a la exposición de los plaguicidas. 


\section{Metodología}

\section{1. Área de estudio}

Para la presente investigación se seleccionó el departamento de Matagalpa (Ilustración 1) como área de estudio. En éste se estima que existen, según el Ministerio de Salud (MINSA, 2001), alrededor de 42 comercializadores y expendios comerciales. Los municipios de Matagalpa y Sébaco fueron seleccionados debido a que centralizan la mayor cantidad de agro servicios registrados en el departamento, con $47.6 \%$ y $19.0 \%$ respectivamente. También se seleccionó a Ciudad Darío (4.8\%) como un tercer municipio por su cercanía con los primeros.

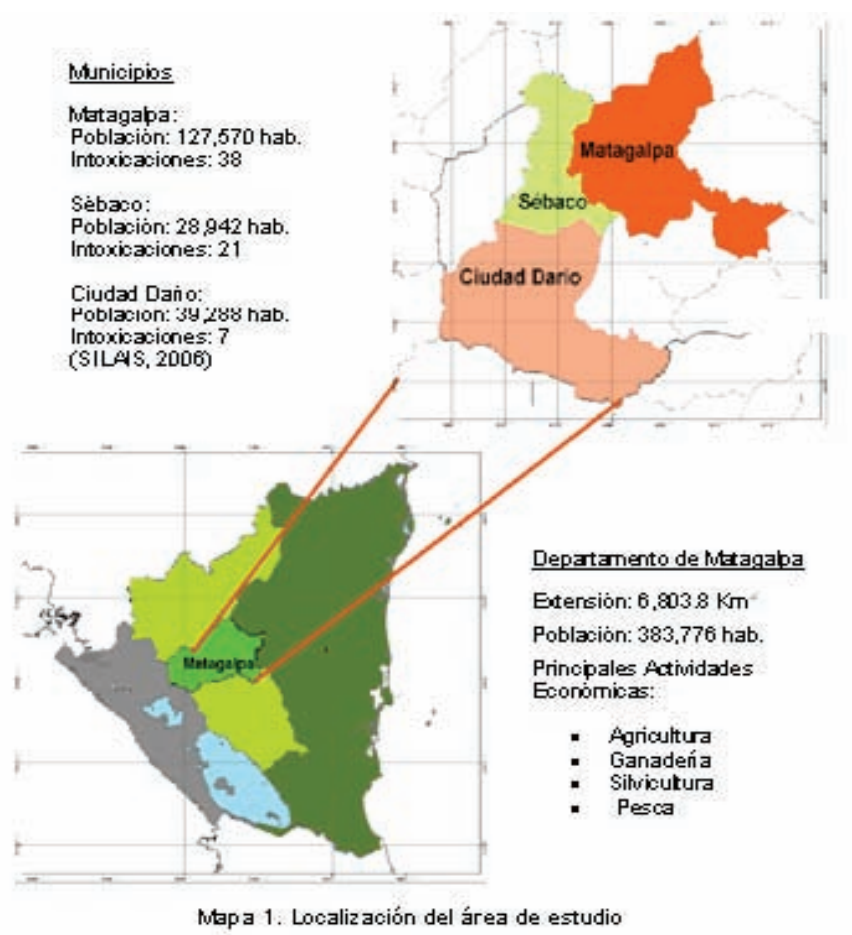

Ilustración 1: Localización del área de estudio

\subsection{Muestra de estudio}

Las muestras de todos los individuos participantes fueron tomadas con previo consentimiento. La investigación se realizó con 30 muestras biológicas (sangre periférica e hisopado bucal) provenientes de personas del sexo masculino expuestas a plaguicidas a nivel de agroservicios (grupo expuesto) y 30 muestras de personas del mismo sexo no expuestas ocupacionalmente a plaguicidas (grupo control). Se obtuvo información sobre hábitos personales y prácticas laborales utilizando una encuesta complementada con observación in situ. 


\section{Criterios de selección:}

- Ser hombre en edad de 18 a 75 años.

- No padecer de anemia.

- No haber ingerido bebidas alcohólicas en las 24 horas previas al muestreo.

- No haber laborado en gasolineras y/o fotocopiadoras.

\subsection{Micronúcleos en células bucales (MNBC)}

Las muestras fueron preparadas para el conteo en el Centro de Biología Molecular (CBM) de la UCA y analizadas en el Institut fur Innenraum und Umwelttoxikologie (Instituto de Toxicología Ambiental y de Interiores) de la Universidad Justus-Liebig de Giessen, Alemania.

La toma y preparación de las muestras para su transporte y conteo se llevó a cabo mediante el siguiente procedimiento: Con la boca previamente enjuagada con agua se tomaron células bucales del sujeto con un cepillo dental nuevo, frotando la parte interna de las mejías, (cachetes o carrillos). Posteriormente se enjuagó el cepillo dental en $20 \mathrm{ml}$. de solución buffer (0.1M EDTA, 0.01 Tris y $0.02 \mathrm{M} \mathrm{NaCl}, \mathrm{pH}$ 7). Luego se transportaron las muestras al laboratorio a una temperatura de $4^{\circ} \mathrm{C}$. Se lavaron las muestras con la misma solución buffer centrifugando a $1500 \mathrm{rpm}$ durante 10 minutos. Se tomaron $50 \mu \mathrm{l}$ de la suspensión celular y se colocaron en un portaobjetos. Se tiñeron con los tintes celulares no específicos para ADN: Giemsa y MayGruwald. Se dejaron secar por 4 horas a $37^{\circ} \mathrm{C}$. Y finalmente se protegió el portaobjeto con un plástico líquido (ENTELAN ®).

El análisis y conteo de micronúcleos se realizó mediante observación en un microscopio eléctrico a 40X, contando el número total de micronúcleos por cada 2000 células observadas.

\subsection{Acetilcolinesterasa eritrocitaria (AChE)}

Para la prueba de acetilcolinesterasa eritrocitaria (AChE) se escogieron 60 muestras de sangre periférica, de las cuales 30 correspondían a individuos expuestos y 30 a individuos del grupo control. Dichas muestras fueron enviadas al Centro Nacional de Diagnóstico y Referencia del MINSA, donde se realizó la prueba mediante aplicación del Método Titrimétrico o Consumo de Hidróxido de Sodio (NaOH). El Método Titrimétrico se basa en la reacción de hidrólisis enzimática de la acetilcolina por la acción de la enzima colinesterasa, formándose una cantidad equivalente de colina y ácido acético. La cantidad de ácido acético se determina por valoración con solución de hidróxido de sodio $0.01 \mathrm{~N}$ y como indicador se utiliza el bromotimol azul.

\subsection{Determinación de mutaciones en gen CYP2D6}

Para determinar la susceptibilidad genética a los efectos genotóxicos de los plaguicidas se tomaron 4 muestras al azar de sujetos expuestos y controles. Las razones para determinar el tamaño de la muestra fueron los altos costos y el tiempo requerido para el análisis. Se utilizó el gen CYP2D6 con mutaciones en tres diferentes exones (5, 6 y 9) que han sido bien 
caracterizados como marcadores moleculares y están involucrados en el metabolismo de compuestos xenobióticos. Este gen pertenece a la familia de los CYP450 y sus polimorfismos están asociados con enfermedades como el cáncer y neurodegenerativas como el Parkinson (Hung, 2004 \& Viaggi et al., 2006). Para tal efecto, se realizó primero un aislamiento del ADN, una amplificación de los segmentos de interés (exones) utilizando cebadores específicos y por último se realizó la identificación de las bandas de ADN haciendo uso de electroforesis y revelado en luz ultravioleta.

El procedimiento, en breve, fue el siguiente: Se aisló ADN siguiendo el protocolo aprobado por la Sección de Genómica de Cáncer del Instituto Nacional de Salud de los Estados Unidos de América (NCI, 2004) con algunas modificaciones. La amplificación del ADN se realizó con cebadores (primers) específicos para identificar los polimorfismos del gen CYP2D6 de esta investigación, que fueron diseñados en el CBM-UCA por el MSc Ian Roustan Espinoza, utilizando el software Biology WorkBench $3.2 \AA$, Oligonucleotid Property Calculator ${ }^{\circledR}$ y Primer 3®.

\subsection{Análisis y procesamiento de información}

Para el análisis estadístico de los datos obtenidos mediante la encuesta y la relación de las variables de interés, se utilizó el programa SPSS 11.0 (Chicago, IL). Las pruebas realizadas fueron de estadística descriptiva, comparaciones simples, correlación de Pearson y $\mathrm{T}$ de Student, entre los grupos de distintos lugares de muestreo, entre expuestos y no expuestos.

El análisis del material cartográfico de la zona en lo concerniente al tema de investigación, se llevó a cabo mediante el programa ArcView GIS para análisis de información geográfica. Mediante éste se elaboró el mapa de ubicación del área de estudio con la ubicación geográfica de los agroservicios muestreados (no se muestra en esta publicación). 
La metodología utilizada en la investigación se resume en la siguiente ilustración.

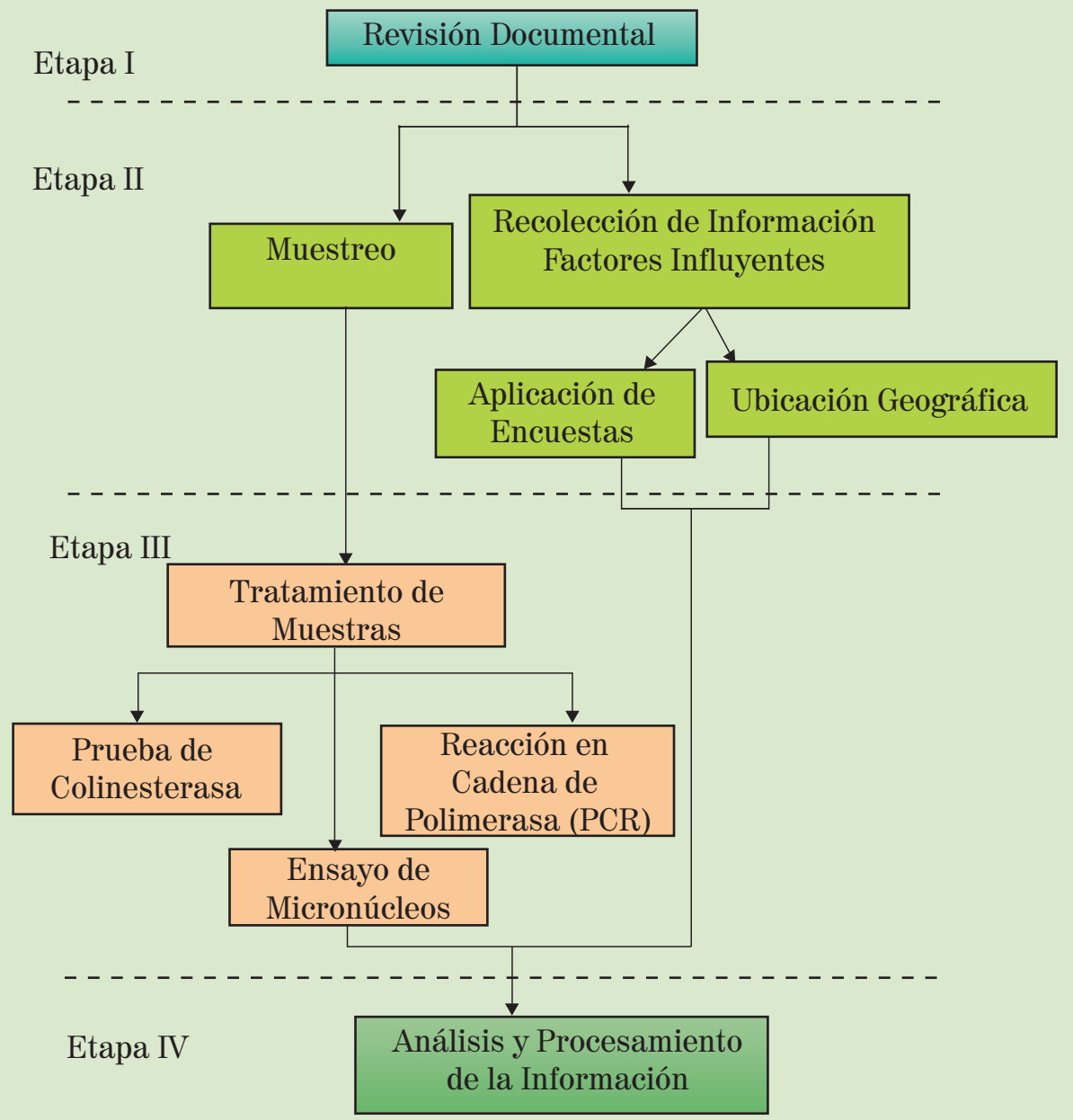

Ilustración 2. Etapas del proceso investigativo 


\section{Resultados y discusión}

\subsection{Encuesta y observación in situ}

Los resultados de la encuesta sobre los factores influyentes son resumidos en el siguiente cuadro:

Cuadro 1. Resumen de resultados de la encuesta.

\begin{tabular}{|c|c|c|c|c|}
\hline \multirow{2}{*}{$\begin{array}{c}\text { Encuesta realizada a traba- } \\
\text { jadores de agroservicios y } \\
\text { muestras controles }\end{array}$} & \multicolumn{2}{|c|}{ Controles } & \multicolumn{2}{|c|}{ Expuestos } \\
\hline & $\mathbf{N}$ & Media \pm SE & $\mathbf{N}$ & Media $\pm \mathrm{SE}$ \\
\hline Total & 30 & - & 30 & - \\
\hline Edad (años) & $19-60$ & $34.7 \pm 11.5$ & $19-60$ & $32.7 \pm 12.9$ \\
\hline \multicolumn{5}{|l|}{ Hábitos de bebida } \\
\hline Ron (L/semana) & 3 & $0.4 \pm 0.3$ & 6 & $1.0 \pm 1.1$ \\
\hline Cerveza (L/semana) & 16 & $2.1 \pm 2.5$ & 13 & $3.2 \pm 4.5$ \\
\hline Café (tazas/semana) & 26 & $15.1 \pm 13.2$ & 30 & $16.8 \pm 14.3$ \\
\hline Té (tazas/semana) & 0 & - & 0 & - \\
\hline \multicolumn{5}{|l|}{ Hábitos de fumado } \\
\hline Fumador & 10 & - & 13 & - \\
\hline Ligero (<5/semana)) & 3 & $1.3 \pm 0.6$ & 0 & - \\
\hline Medio (6-15/semana) & 3 & $11.7 \pm 2.9$ & 5 & $11.2 \pm 3.3$ \\
\hline Pesado (>15 semana) & 4 & $40.0 \pm 16.3$ & 8 & $43.5 \pm 21.5$ \\
\hline No fumador & 15 & - & 19 & - \\
\hline \multirow{3}{*}{$\begin{array}{l}\text { Ex-fumador } \\
\text { Encuesta realizada a traba- } \\
\text { jadores de agroservicios y } \\
\text { muestras controles }\end{array}$} & 5 & - & 0 & - \\
\hline & \multicolumn{2}{|c|}{ CONTROLES } & \multicolumn{2}{|c|}{ EXPUESTOS } \\
\hline & $\mathbf{N}$ & Media \pm SE & $\mathrm{N}(\%)$ & Media $\pm \mathrm{SE}$ \\
\hline \multicolumn{5}{|l|}{ Salud } \\
\hline Problemas respiratorios & 0 & - & 0 & - \\
\hline Alergias & 2 & - & 2 & - \\
\hline Dermatitis & 0 & - & 2 & - \\
\hline Dolores de cabeza o náusea & 0 & - & 2 & - \\
\hline \multicolumn{5}{|l|}{ Condiciones de trabajo } \\
\hline Años de exposición & - & - & $6 \pm 6.1$ & - \\
\hline Uso de equipo de seguridad: & - & - & 15 & \\
\hline $\begin{array}{l}\text { Infraestructura de seguridad } \\
\text { Puntaje de cumplimiento } \\
(\mathrm{PC}=0 \text { - 10) }\end{array}$ & & & & $6.8 \pm 2.4$ \\
\hline Capacitados & & & 16 & \\
\hline
\end{tabular}


Los datos observados en el Cuadro 1 muestran una comparación entre los resultados obtenidos mediante la encuesta realizada a los dos grupos de investigación. Es importante señalar que, para fines del análisis, en dicha comparación no se reflejan diferencias significativas entre los resultados de ambos grupos en características como consumo de licor, café o tabaco de manera global, lo que significa que los efectos de consumo de estas sustancias no van a repercutir en diferencias en cuanto a las pruebas de colinesterasa y MN.

Se observó que el total de los encuestados que respondieron positivamente al preguntárseles sobre la tenencia y uso de equipos de protección personal (EPP), no utilizaba este equipo a la hora de la visita. En este sentido, se encontró que un 50\% (15) de los expuestos afirmó haber recibido capacitación para el trabajo desempeñado, siendo la mayoría de las capacitaciones proporcionada por el Estado a través del Ministerio Agropecuario y Forestal (MAGFOR), seguido de los distribuidores de plaguicidas, y en menor escala por el MINSA y los empleadores.

De los 20 establecimientos comerciales visitados, 16 ocupan un sitio exclusivo para el negocio, en tanto que los 4 restantes se encuentran ubicados en casas de habitación. Así mismo, 10 se ubican en los mercados municipales, 8 en barrios y uno solo en las afueras de la ciudad al lado de establecimientos comerciales de naturaleza similar.

Los sitios de interés más frecuentemente encontrados en las cercanías de los agroservicios fueron casas de habitación, puestos de alimentos y almacenes de uso cotidiano. Sin embargo, también se observaron colegios, bares, farmacias y al menos 10 de los agroservicios visitados se encontraban a escasos metros de cauces, en los que la lluvia y otros agentes ambientales podrían transportar los químicos hasta las fuentes de agua más cercanas, en caso de derrames accidentales o provocados.

Entre los plaguicidas encontrados en más del 60\% de los agroservicios existen aquellos que se han probado como agentes genotóxicos, dentro de los cuales hay varios organofosforados como paratión y compuestos organoclorados como 2,4 D. (Garret et al., 1986), y otros como Metamidofós, Endosulfan y Paraquat, que han sido sacados del mercado internacional o fuertemente restringidos por su alta persistencia en el ambiente y daños a la salud.

Cuadro 2. Plaguicidas más comunes encontrados

\begin{tabular}{|l||l||l||l||}
\hline \multicolumn{1}{|c||}{ Organofosforado } & Carbamato & Orga noclorado & \multicolumn{1}{|c||}{ Otros } \\
\hline *Metamidofós (MTD) & & $2,4 \mathrm{D}$ & \\
Glifosatos (Glifosan) & Vidate & *Endosulfan & \\
Malatión & Drametrin & Oxicloruro de & *Paraquat \\
Terbusag & Nudrin & cobre & (Gramoxone) \\
Diazinon & Carbofurán & & Cipermetrina \\
Clorpirifós & Metomex & & \\
Metil Paratión & & & \\
\hline
\end{tabular}

*Plaguicidas altamente restringidos a nivel mundial 


\subsection{Prueba de colinesterasa}

Las pruebas de AChe reflejan una mayor cantidad de valores anormales de la enzima en los comerciantes de plaguicidas que en controles (6:1), lo que corresponde a inhibición por plaguicidas organofosforados y carbamatos.

Cuadro 3. Nivel de colinesterasa

\begin{tabular}{|c|c|}
\hline GRUPO & $\begin{array}{c}\text { *Valores anormales de } \\
\text { colinesterasa }\end{array}$ \\
\hline Control & 1 \\
\hline Expuestos & $6^{\mathrm{a}}$ \\
\hline
\end{tabular}

aDiferencia significativa entre grupos Control y Expuestos ( $\mathrm{z}=2.5$, IC: $99 \%$ )

*Valores normales: $0.35-0.45 \mathrm{ml}$ consumidos de $\mathrm{NaOH} 0.01 \mathrm{~N}$ o $>62.5 \%$ Método de Lovibond.

En el caso de la muestra tomada se espera que los valores se encuentren estrechamente relacionados con el contacto de los individuos muestreados con plaguicidas a causa de la actividad desempeñada. Sin embargo, es importante mencionar que pueden existir valores por debajo de la referencia no sólo debido a los plaguicidas, sino a factores tales como la nutrición, el estado de salud, la variabilidad genética, y quizás el único sujeto con valores bajos de colinesterasa en los controles se deba a estas razones.

El único sujeto afectado del grupo control no consumía licor, no fumaba y nunca había trabajado con plaguicidas. Sin embargo, poseía familiares con cáncer y asma, lo que sugiere alguna deficiencia genética.

\subsection{Ensayo de micronúcleos}

Los resultados resumidos en el Cuadro 4 muestran la frecuencia de micronúcleos obtenidos de individuos expuestos ocupacionalmente a plaguicidas, en comparación con una población no expuesta de la misma localidad. La información fue analizada para conocer el efecto de la edad, del fumado y del tiempo de exposición a los plaguicidas. 
Cuadro 4. Frecuencia de micronúcleos encontrados en comerciantes de plaguicidas y grupo control en células epiteliales.

\begin{tabular}{||c|c|c|c||}
\hline Estadísticos & $\begin{array}{c}\text { MN/2000 células } \\
\text { (Promedio } \pm \text { Desviación estándar) }\end{array}$ & Rango & N \\
\hline $\begin{array}{c}\text { 1. MN en grupo } \\
\text { Control }\end{array}$ & $3.63 \pm 1.3$ & $5(1-6)$ & 30 \\
\hline 2. MN en Expuestos & $6.23 \pm 2.2^{\mathrm{a}}$ & $9(2-11)$ & 30 \\
\hline
\end{tabular}

2. $1 \mathrm{MN}$ en grupo expuestos agrupados por edad

\begin{tabular}{||c|c|c|c|}
\hline $\begin{array}{c}\text { MN en Edad } \\
19-30\end{array}$ & $6.53 \pm 2.8$ & $9(2-11)$ & 15 \\
\hline $\begin{array}{c}\text { MN en Edad } \\
31-42\end{array}$ & $5.77 \pm 1.7$ & $5(3-8)$ & 9 \\
\hline $\begin{array}{c}\text { MN en Edad } \\
43-61\end{array}$ & $6.16 \pm 0.7^{\mathrm{b}}$ & $2(5-7)$ & 6 \\
\hline
\end{tabular}

2.2 MN en comerciantes agrupados por tiempo de exposición (TE) en años

\begin{tabular}{|c|c|c|c|}
\hline MN en TE 0.5-3 & $5.90 \pm 2.6$ & $7(2-9)$ & 11 \\
\hline MN en TE 3-9 & $6.08 \pm 2.5$ & $9(2-11)$ & 13 \\
\hline MN en TE 10-25 & $6.33 \pm 1.03^{c}$ & $3(5-8)$ & 6 \\
\hline
\end{tabular}

2.3 MN en grupo comerciantes agrupados por fumado

\begin{tabular}{|c|c|c|c|}
\hline MN en Fumador & $5.80 \pm 2.7$ & $9(2-11)$ & 10 \\
\hline MN en No Fumador & $6.45 \pm 2.0^{\mathrm{C}}$ & $7(3-10)$ & 20 \\
\hline
\end{tabular}

${ }^{a}$ Diferencia muy significativas entre los grupos expuestos y control (con un valor $\mathrm{P}<0.001 \mathrm{y}$ $\mathrm{IC}=99 \%$ ).

${ }^{\mathrm{b}}$ Diferencia entre grupos de edades no significativa (con un valor $\mathrm{P}=0.277 \mathrm{y} \mathrm{IC}=95 \%$ ).

${ }^{\mathrm{C}}$ Diferencia no significativa (con un valor $\mathrm{P}>0.05 \mathrm{y} \mathrm{IC}=95 \%$ ).

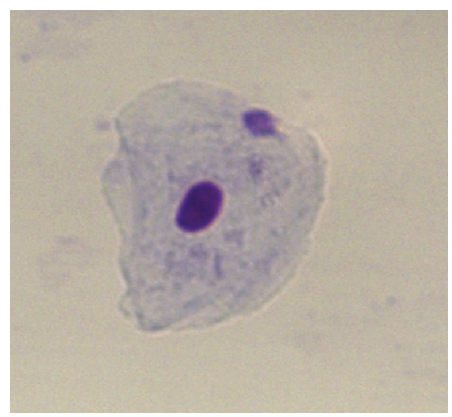

Ilustración 3. Micronúcleo en célula epitelial

Fuente: Fotografía en microscopio a 40X por Dr. Richard Gminski, Universidad JustusLiebig-Giessen. Alemania. 
En la Ilustración 3 se puede apreciar un micronúcleo en una célula epitelial de tamaño considerable, lo que representa un cromosoma completo, mientras que los MN pequeños se consideran como fragmentos de cromosomas separados del núcleo.

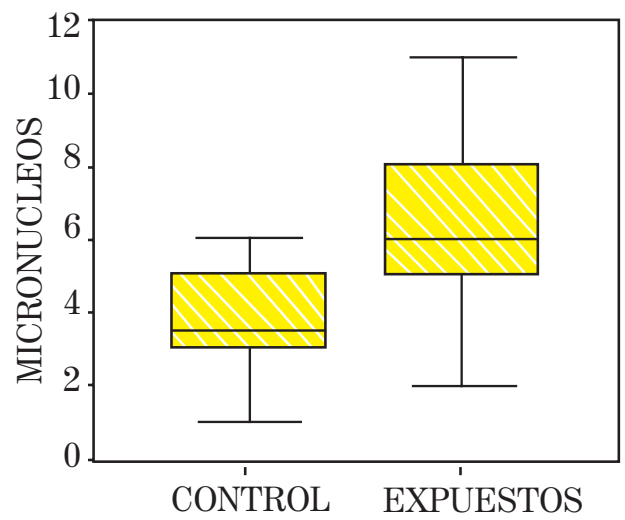

Ilustración 4. Cajas MN en Expuestos y Control $(\mathrm{P}<0.001$ y IC $=99 \%)$

El grupo de personas expuestas a plaguicidas refleja una frecuencia significativamente mayor con respecto al control $(\mathrm{P}<0.001 \mathrm{y} \mathrm{IC}=99 \%)$, teniendo a su vez, mayor variabilidad en los datos, lo que comprueba el efecto genotóxico de los plaguicidas.

Comparando la frecuencia de MN con la presentada en otros estudios se observa que los datos están dentro de los rangos comunes, tomando en cuenta el método de tinción -ya que con Giemsa se espera un mayor número de MN que con otros medios de tinción como Feulgen o DAPI (Nersesyan et al., 2006).

Los resultados concuerdan con estudios como los de Carbonell et al. (1993), Figgs et al. (2000) y Gómez et al. (2000), que encontraron diferencias significativas entre controles y expuestos. Este último encontró en México diferencias entre floricultores expuestos a plaguicidas y un grupo control.

Sin embargo, hay otros estudios en los que no se encuentran efectos genotóxicos a pesar de exposición a plaguicidas, lo que podría atribuirse a la puesta en práctica de medidas/ equipos de seguridad y al tipo de exposición (tiempo, intensidad y tipo de plaguicida), como se refleja en estudios realizados por Carbonell et al. (1990) y por Pastor et al. (2001 y 2002) en poblaciones europeas de Grecia y Hungría.

Los expuestos agrupados por fumado, edad y tiempo de exposición, no reflejaron diferencias significativas $(\mathrm{IC}=95 \%)$, aunque los grupos de tiempo de exposición reflejan una tendencia a incrementar. 


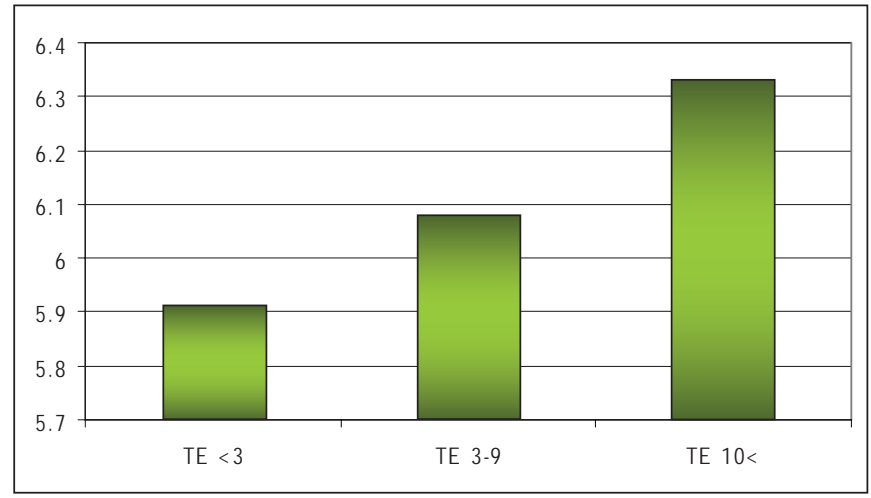

Ilustración 5. Frecuencia de MN por tiempo de exposición (años).

La relación del tiempo de exposición, aquí descrito en años, es una medida general de expresar la exposición. Se percibe un leve incremento en la frecuencia de MN a medida que el sujeto labora como comerciante de plaguicidas por más tiempo. Sin embargo, esto es sólo una tendencia ya que las diferencias no son significativas como se ha encontrado en estudios anteriores, como los de Bolognesi et al. (1993) y Gómez et al. (2000). La tendencia concuerda con estudios en los que se demuestra que a mayor exposición a la sustancia tóxica, mayor es el efecto.

\subsection{Determinación de mutaciones en gen CYP2D6 (PCR)}

El tamaño de las bandas encontradas en el gel de agarosa, correspondientes a los polimorfismos encontrados en el gen CYP2D6 de 4 individuos, 2 expuestos y 2 controles, reflejan mutaciones en los exones 5 y 6 con tamaños de $1445 \mathrm{pb}$ y $1405 \mathrm{pb}$ respectivamente. En cambio, las bandas del exón 9 no fueron específicas y no se logró determinar un tamaño de banda.

Las siguientes fotografías muestran los resultados correspondientes a:

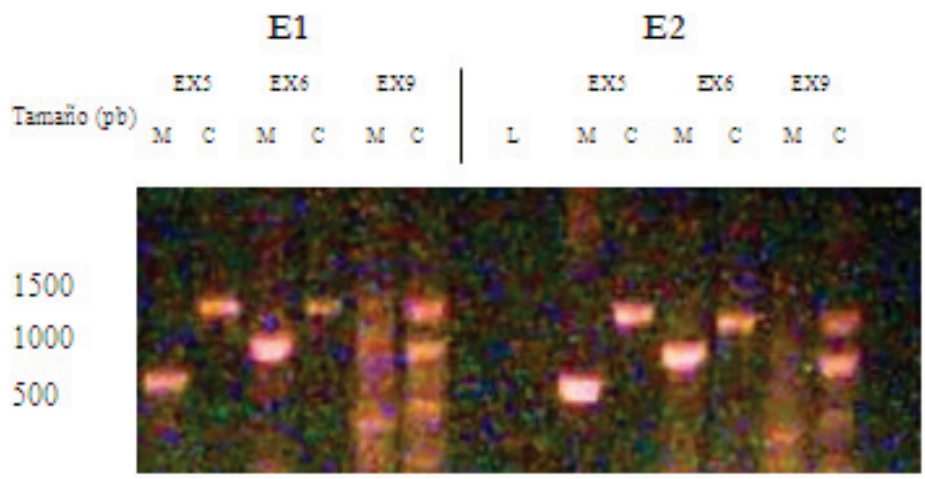


2 comerciantes de plaguicidas (expuestos a plaguicidas)

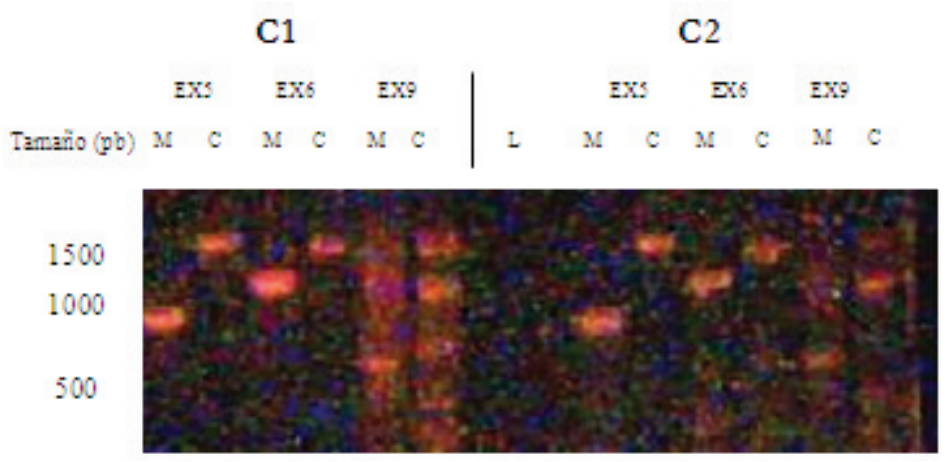

2 sujetos controles (no expuestos ocupacionalmente a plaguicidas)

Esta es la primera vez que se reporta este gen CYP2D6 -de importancia metabólica para plaguicidas en la población nicaragüense- y al no conocer su frecuencia se comparó con estudios en donde se ha tomado en cuenta este gen y los efectos de los plaguicidas, encontrándose que los defectos en este gen afectan la susceptibilidad de la acetilcolinesterasa a ser reducida por organofosforados, pero no por carbamatos (Costa et al. 2003) y que en los individuos con menor capacidad metabolizadora del gen, se observa un mayor riesgo a ciertos agentes neurotóxicos (Matoh et al. 2003).

La información sobre mutaciones en el gen CYP2D6 en esta investigación es de carácter exploratorio y requiere de una investigación más profunda al respecto, tomando en cuenta más sitios de mutación, una muestra mayor, así como secuenciación de nucleótidos específicos.

\section{Conclusiones}

A partir de los resultados obtenidos se concluye que:

- El ensayo de micronúcleos en células epiteliales demostró un incremento significativo en daño genético en comerciantes de plaguicidas, lo que representa un riesgo de envejecimiento prematuro y desarrollo de enfermedades.

- Los comerciantes de plaguicidas estudiados se encuentran afectados por inhibición de acetilcolinesterasa, afectándose el sistema nervioso.

- Existe un incumplimiento de regulación respecto a la localización de agroservicios y las condiciones de trabajo e infraestructura que garanticen la seguridad del trabajador y la respuesta rápida ante accidentes. 


\section{Recomendaciones}

A partir de las dificultades encontradas durante el proceso investigativo se propone:

- Establecer convenios entre los ministerios y los institutos de investigación del país con el objetivo de reunir esfuerzos, experiencias y recursos en la realización de investigaciones de interés nacional.

- Promover investigaciones que complementen los resultados obtenidos en el presente estudio (como evaluar la calidad genotóxica del agua) y realizar réplicas del mismo en otras zonas del país.

- Investigar la presencia y distribución de polimorfismos de genes de interés metabólico en la población nicaragüense con el objetivo de conocer la susceptibilidad de la población a diferentes compuestos y tomar medidas al respecto.

\section{Agradecimientos}

Agradecemos a numerosas organizaciones y personas que hicieron posible esta investigación, dentro de las cuales se destaca el apoyo brindado por el equipo del Centro de Biología Molecular (CBM-UCA) con fondos de New England Biolabs, Ine (NEB, EEUU), Agencia Alemana de Intercambio Académico (DAAD), Universidad Justus-Liebig (Giessen), Laboratorio AZBA (Berlín), Servicio de Información Mesoamericana sobre Agricultura Sostenible (SIMAS), Centro Nacional de Toxicología (CNT-MINSA) y Hospital Alemán Nicaragüense (HAN). También agradecemos a personas que aportaron significativamente a la investigación, como el MSc. Ian Roustan Espinosa, el Msc. Ernesto Flores, la Lic. Raquel Vargas, la Ing. Ambiental Yasica Sequeira León y el Lic. Epidemiología Byron García. Las personas que revisaron y brindaron consejos fueron: la Dra. Jackeline Berroterán, el Msc. Iván Guevara y el Dr. Jeffrey McCrary. Agradecemos también a todos los voluntarios del departamento de Matagalpa.

\section{Referencias bibliográfícas}

ALBERTINI, R.; ANDERSON, D.; DOUGLAS, G.; HAGMAR, L.; HEMMINKI, K. \& MERLO, F. et al. (2000). IPCS Guidelines for the Monitoring of Genotoxic Effects of Carcinogens in Humans. International Programme on Chemical Safety. Mutat Res; 463(2):111-172.

AU, W.; SIERRA-TORRES, C.; CAJAS-SALAZAR, N.; BRYAN, S \& LEGATOR, M. (1999). "Cytogenetic Effects from Exposure to Mixed Pesticides and the Influence from Genetic Susceptibility". Environmental health Perspective. Jun;107(6):501-5.

BOLOGNESI, C.; PARRINI, M.; BONSÁI, S.; IANELLO, G. \& SALATINO, A. (1993). “Cytogenetic Analysis of a Human Population Occupationally Exposed to Pesticides". En Mutation Research. Feb;285(2):239-49.

CARBONELl, E.; PUIG, M.; XAMENA, N.; CREUS, A. \& MARCOS, R. (1990). "Sister Chromatid Exchange in Lymphocytes of Agricultural Workers Exposed to Pesticides". 
En Mutagenesis, 5: 403-405.

CARBONELL, E.; XAMENA, N.; CREUS, A. \& MARCOS, R. (1993). “Cytogenetic Biomonitoring in a Spanish Group of Agricultural Workers Exposed to Pesticides”. En Mutagenesis 8: 511-517.

COSTA, C.;CATANIA, S.\&SILVARI, V.(2003). “GenotoxicityandActivation of Organophosphate and Carbamate Pesticides by Cytochrome P450 2D6”. En Italian Journal of Medicine and Ergonomy. Jul-Sep;25 Suppl(3):81-2.

FIGGS, L.; HOLLAND, N.; ROTHMANN, N.; ZAHM, S.; TARONE, R.; HILL, R.; VOGT, R.; SMITH, M.; BOYSEN, C.; COLMES, F.; VAN DYCK, K. \& BLAIR, A. (2000). "Increased Lymphocyte Replicative Index Following 2,3-Dichlorophenoxyacetic Acid Herbicide Exposure". En Cancer Causes Control. Apr; 11(4):373-80.

GARRET, N.; STACK, H. \& WATERS, M. (1986). Evaluation of the Genetic Activity Profiles of 65 Pesticides. Washington, D.C.: U.S. Environmental Protection Agency, EPA/600/J$86 / 415$.

GÓMEZ, S.; DÍAZ, Y.; MENESES, M.; VILLALOBOS, F. \& DE LEÓN, J. (2000). “Cytogenetic Biomonitoring in a Mexican Floriculture Worker Group Exposed to Pesticides". En Mutation Research 466. P 117-124.

HENAO, S. \& ARBELAEZ, M. (2002). "Epidemiologic Situation of Acute Pesticide Poisoning in Central America, 1992-2000”. En Epidemiologic Bulletin. Sep;23(3):5-9.

HUNG, R. (2004). "Interactions with Environmental Exposures and Bladder Cancer Risk in a High-Risk Population”. En International Journal of Cancer. GST, NAT, SULT1A1, CYP1B1 Genetic Polymorphisms._Jul 1;110(4):598-604.

INCAP; PLAGSALUD; ECO \& UNED. (1999). Diagnóstico, tratamiento y prevención por intoxicaciones agudas causadas por plaguicidas. San José: INCAP; PLAGSALUD; ECO \& UNED, Tercera edición.

MATOH, N.; TANAKA, S.; TAKEHASHI, M.; BANASIK, M.; STEDEFORD, T.; MASLIAH, E.; SUZUKI, S.; NISHIMURA, Y. \& UEDA K. (2003). "Overexpression of CYP2D6 Attenuates the Toxicity of MPP+ in Actively Dividing and Differentiated PC12 Cells". En Gene Expression. 11(3-4):117-24.

MINSA. (2006). "Reporte anual de intoxicaciones 2006”. Managua: MINSA.

MINSA; OPS; OMS. (2001). "Diagnóstico de la exposición y efectos del uso de los plaguicidas en Matagalpa”. Managua: casa editorial.

National Institute of Health Section of Cancer Genomics, Genetics Branch, NCI. (2004). DNA Preparation from Blood. United States of America. Pg. 3.

NERSESYAN, A.; KUNDI, M.; ATEFIE, K.; SCHULTE-HERMANN, R. \& KNASMULLER, S. (2006). "Effect of Staining Procedures on the Results of Micronucleus Assays with Exfoliated Oral Mucosa Cells”. En Cancer Epidemiol Biomarkers Prev; 15(10).

PASTOR, S.; CREUS, A.; XAMENA, N.; SIFFEL, C. \& MARCOS, R. (2002). "Occupational Exposure to Pesticides and Cytogenetic Damage: Results of a Hungarian Population Study Using the Micronucleus Assay in Lymphocytes and Buccal Cells”. En. Environ Mol Mutagen.;40(2):101-9

PASTOR, S.; GUTIÉRREZ, S.; CREUS, A.; XAMENA, N.; PIPERAKIS, S. \& MARCOS, R. (2001). "Cytogenetic Analysis of Greek Farmers Using the Micronucleus Assay in Peripheral Lymphocytes and Buccal Cells". En Mutagenesis. Nov;16(6):539-45

PLAGSALUD; OPS; OMS (2003). "Plaguicidas a restringir en Centroamérica", San José: OPS; OMS, primera edición. 